\title{
Synthesis and Some Physical Properties of New Organometallic Compounds Containing Si and Sn Atoms ${ }^{+}$
}

\author{
V. Fabricio Terraza ${ }^{1,2}$, Darío C. Gerbino ${ }^{1,3}$ and Julio C. Podestá 1,* \\ 1 INQUISUR, Departamento de Química, Universidad Nacional del Sur (UNS)-CONICET, \\ Avenida Alem 1253, 8000 Bahía Blanca, Argentina; fabricioterraza87@hotmail.com (V.F.T.); \\ dgerbino@uns.edu.ar (D.C.G.) \\ 2 CIC-PBA, 1900 La Plata, Argentina \\ 3 CONICET, C1425FQB Ciudad Autónoma de Buenos Aires, Argentina \\ * Correspondence: jpodesta@uns.edu.ar \\ + Presented at the 22nd International Electronic Conference on Synthetic Organic Chemistry, \\ 15 November-15 December 2018. Available Online: https://sciforum.net/conference/ecsoc-22 \\ Published: 14 November 2018
}

\begin{abstract}
This paper reports the synthesis of two new organotin hydrides containing a (phenyldimethylsilyl)methyl ligand. It was found that the reaction of (phenyldime thylsilyl) methylmagnesium bromide in ether afforded ((phenyldimethylsilyl)methyl) trimethyltin (3) (72\%), and with (-)-menthyldimethyltin bromide (4) gave (((phenyl dimethylsilyl)methyl)(1R,2R,5R) -2-isopropyl-5-methylcyclohexyl)dimethyltin (5) (84\%). Bromo dealkylation of 3 with bromine in $\mathrm{MeOH}$ led to ((phenyldimethylsilyl)methyl)dimethyltin bromide (6) (82\%), which upon reduction with $\mathrm{LiAlH}_{4}$ yielded ((phenyldimethyl silyl)methyl)dimethyltin hydride (7) $(95 \%)$. The best method for obtaining the corresponding bromostannylated derivative of compound 5, i.e., (((phenyldimethylsilyl) methyl)(1R,2R,5R)-2-isopropyl-5-methylcyclohexyl) methyltin bromide (8) was the exchange reaction between 4 and $\mathrm{HgBr}_{2}$ that led to 8 with $90 \%$ yield. The reduction of bromide 8 with $\mathrm{LiAlH}_{4}$ gave a diastereomeric mixture of (((phenyldimethylsilyl)methyl)(1R,2R,5R)-2-isopropyl-5methylcyclohexyl)methyltin hydride (9). Some physical properties and ${ }^{1} \mathrm{H},{ }^{13} \mathrm{C}$, and ${ }^{119} \mathrm{Sn}$ NMR of the new organotin hydrides, as well as that of their intermediate precursors are included.
\end{abstract}

Keywords: organotin silicon compounds; tin-(-)-menthyl derivatives; organotin hydrides

\section{Introduction}

Organotin hydrides have found many applications in organic synthesis, not only as reducing reagents, but also as intermediates in the generation of carbon-carbon bonds, and for the preparation of compounds, such as vinylstannanes, which are invaluable starting materials for cross-coupling reactions [1-3]. In previous studies, we have shown that the size of organic ligands attached to a tin atom affects not only the reactivity, but also the stereoselectivity of the reactions of these compounds [4]. We have also reported the synthesis of tin compounds containing three and two phenyldimethylsilyl)methyl ligands [5,6]. Now, following our investigations on the relationship between the steric volume of the substituents attached to the tin atom and the reactivity, as well as the stereoselectivity of the reactions of organotin hydrides, we considered it important to carry out the synthesis of (((phenyldimethylsilyl)methyl)(1R,2R,5R)-2-isopropyl-5-methylcyclohexyl) methyltin hydride (9). This would enable us, in turn, to study the chemical properties of this new hydride that contains two bulky substituents: a (phenyldimethylsilyl)methyl group and a (-)-menthyl group attached to the tin atom. 


\section{Results and Discussion}

The synthesis of the starting compounds needed for the study was carried out according to Scheme 1. (Chlorodimetilsilyl)methyl chloride (1) is commercially available.

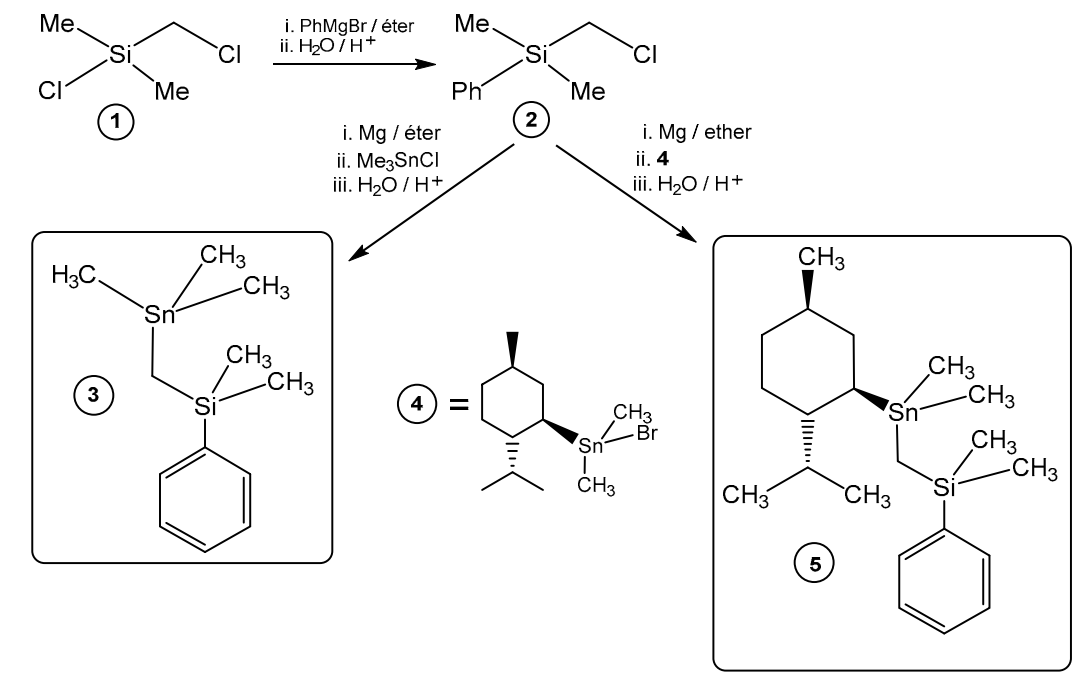

Scheme 1. Synthesis of starting compounds with Sn and Si atoms 3 and 5.

(Phenyldimethylsilyl)methyl chloride (2) was obtained from compound $\mathbf{1}$ following known procedures [3]. In order to develop the best protocol to reach the tin hydrides, we first obtained ((phenyldimethylsilyl)methyl)trimethyltin 3. The alkylation of trimethyltin chloride with (phenyldimethylsilyl)methyl magnesium chloride in THF, using a ratio Grignard reagent/Mes $\mathrm{SnCl}=1.1$, afforded the new ((phenyldimethylsilyl)methyl)trimethyltin (3) in $72 \%$ yield. Similarly, the addition of (-)-menthyldimethyltin bromide (4) in ether to a solution of the same Grignard reagent in THF (ratio Grignard reagent/4 = 1.4) led to (((phenyldimethylsilyl)methyl) $(1 \mathrm{R}, 2 \mathrm{R}, 5 \mathrm{R})-2$-isopropyl-5methylcyclohexyl)dimethyltin (5) in $84 \%$ yield.

The reaction of 3 with bromine (Scheme 2) in methanol-ratio $\mathrm{Br}_{2} / \mathbf{3}=1.1$-led to ((phenyldimethylsilyl)methyl)dimethyltin bromide (6) in $82 \%$ yield (Scheme 2). The reduction of bromide 6 with LiAlH4 in diethylether, under argon atmosphere, gave ((phenyldimethylsilyl) methyl) dimethyltin hydride (7) in $95 \%$ yield.

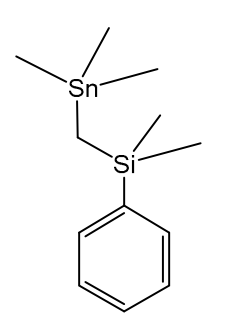

(3)

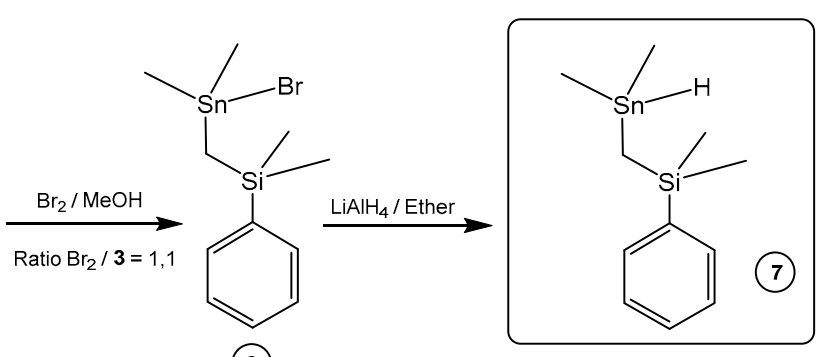

(6)

Scheme 2. Synthesis of ((phenyldimethylsilyl)methyl) dimethyltin hydride (7).

Selected values of ${ }^{1} \mathrm{H},{ }^{13} \mathrm{C}$, and ${ }^{119} \mathrm{Sn}-\mathrm{NMR}$ data of the new organotins are included in Table 1. 
Table 1. Selected ${ }^{1} \mathrm{H}-,{ }^{13} \mathrm{C}-$, and ${ }^{119} \mathrm{Sn}-\mathrm{NMR}$ values of ((phenyldimethylsilyl)methyl)trimethyltin (3), ((phenyldimethylsilyl)methyl)dimethyltin bromide (6), and hydride 7 a

\begin{tabular}{|c|c|c|c|c|}
\hline & & & $\begin{array}{ll}\mathrm{Z} & \mathrm{N}^{0} \\
\mathrm{Me} & 3 \\
\mathrm{Br} & 6 \\
\mathrm{H} & 7 \\
\end{array}$ & \\
\hline & Comp. 3 & Comp. 6 & & Comp. 7 \\
\hline \multicolumn{5}{|c|}{${ }^{13} \mathrm{C}-\mathrm{NMR}$} \\
\hline Me-Sn $\left({ }^{1} \mathrm{~J}\right)$ & $-7.93(334.0)$ & $-0.01(362.0)$ & & $-10.46(347.8)$ \\
\hline$-\mathrm{CH}_{2} \mathrm{Sn}\left({ }^{1} J\right)$ & $-5.30(242.4)$ & $3.88(257.7)$ & & $-7.32(258.0)$ \\
\hline Me-Si [3J(C-Sn)] & $0.28(12.1)$ & -0.16 & & $-0.09(14.1)$ \\
\hline $\mathrm{Ph}-\mathrm{Si}-\mathrm{CH}_{2}-\mathrm{Sn}\left[{ }^{3} J(\mathrm{Ph}-\mathrm{Sn})\right]$ & $141.72(18.4)$ & $139.70(20.1)$ & & $141.10(16.6)$ \\
\hline \multicolumn{5}{|c|}{${ }^{1} \mathrm{H}-\mathrm{NMR}$} \\
\hline $\mathrm{Me}-\mathrm{Sn}\left[{ }^{2} J(\mathrm{Sn}, \mathrm{H}), \mathrm{Hz}\right]$ & $-0.02(\mathrm{~s}, 2 \mathrm{H}, \mathrm{NO})$ & $0.57(56.7)$ & -0.0 & $01(\mathrm{~s}, 3 \mathrm{H}, 56.5) ; 0.00(\mathrm{~s}, 3 \mathrm{H}, 56.5)$ \\
\hline $\mathrm{Me}-\mathrm{Si}$ & $0.57(\mathrm{~s}, 6 \mathrm{H})$ & $0.47 \mathrm{~s}, 6 \mathrm{H})$ & & $0.25(\mathrm{~s}, 6 \mathrm{H})$ \\
\hline $\mathrm{Sn}-\mathrm{CH}_{2}$ & $0.00(\mathrm{~s}, 9 \mathrm{H}, 51,7)$ & $0.72(\mathrm{~s}, 2 \mathrm{H})$ & & $-0.12 \&-0.11(2 \mathrm{~s}, 2 \mathrm{H})$ \\
\hline $\mathrm{Sn}-\mathrm{H}\left[{ }^{1} J(\mathrm{Sn}, \mathrm{H})\right]$ & -- & -- & & $4.85(\mathrm{~m}, 1 \mathrm{H}, 1739.5)$ \\
\hline \multicolumn{5}{|c|}{${ }^{119}$ Sn-NMR } \\
\hline & 9 & 135 & -96[ & $\left.\left({ }^{1} \mathrm{~J}(\mathrm{Sn}, \mathrm{C})=468\right)\right]\left[{ }^{1} \mathrm{~J}(\mathrm{Sn}, \mathrm{H})=1383\right]$ \\
\hline
\end{tabular}

${ }^{a}$ In $\mathrm{CDCl}_{3}$ (compounds 3 and 6 ) and $\mathrm{C}_{6} \mathrm{D}_{6}(7)$; chemical shifts in ppm; nJ(Sn,C) and $\mathrm{nJ}(\mathrm{Sn}, \mathrm{H})$ coupling constants (in brackets) in Hz. Comp.: compound.

Taking into account the previous results, we carried out a study on the halogenation of compound 5 (Scheme 3). The reaction of 5 with bromine in methanol using ratios $\mathrm{Br}_{2} / 5=1.1-2.2$, led in all cases to mixtures of the corresponding mono- and dibromides.

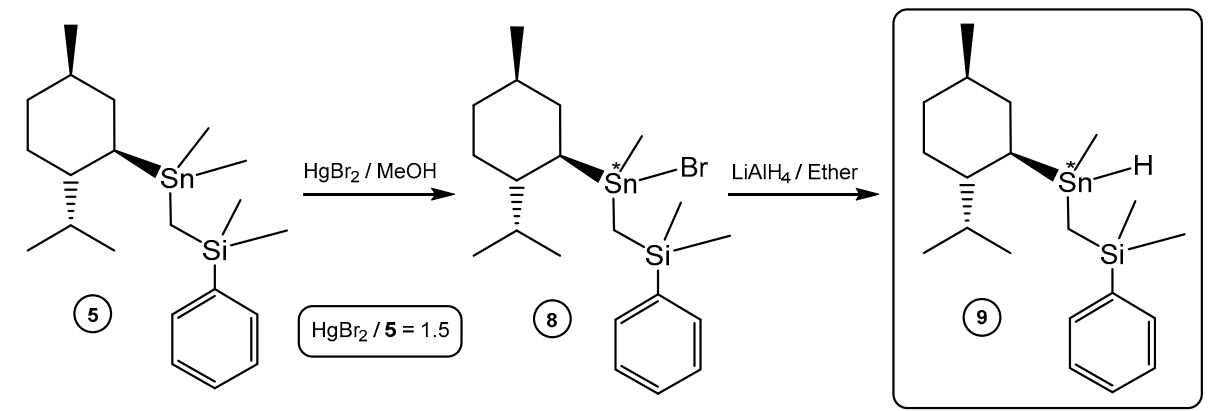

Scheme 3. Synthesis of (((phenyldimethylsilyl)methyl)(1R,2R,5R)-2-isopropyl-5-methyl cyclohexyl) methyltin hydride (9).

On the other hand, the exchange reaction between 5 and $\mathrm{HgBr}_{2}$ in methanol using a ratio of $\mathrm{HgBr}_{2} / 5$ = 1.5 gave exclusively (((phenyldimethylsilyl)methyl)(1R,2R,5R)-2-isopropyl-5-methyl cyclohexyl)methyltin bromide (8) (Scheme 3) in $87 \%$ yield. The reduction of bromide 8 with $\mathrm{LiAlH}_{4}$ in dry diethylether under argon atmosphere, afforded (((phenyldimethylsilyl)methyl) (1R,2R,5R)-2isopropyl-5-methylcyclohexyl)methyltin hydride (9) in 97\% yield.

Selected values of ${ }^{1} \mathrm{H},{ }^{13} \mathrm{C}$, and ${ }^{119} \mathrm{Sn}$-NMR data of the new organotins 5,8 , and 9 are included in Table 2. 
Table 2. Selected ${ }^{1} \mathrm{H}-,{ }^{13} \mathrm{C}-$, and ${ }^{119} \mathrm{Sn}-\mathrm{NMR}$ values of (((phenyl dimethylsilyl)methyl)(1R,2R,5R)2-isopropyl-5-methylcyclohexyl)dimethyltin (5), (((phenyldimethylsilyl)methyl)(1R,2R,5R)-2-isopropyl5-methylcyclohexyl)methyltin bromide (8), and hydride 9 a

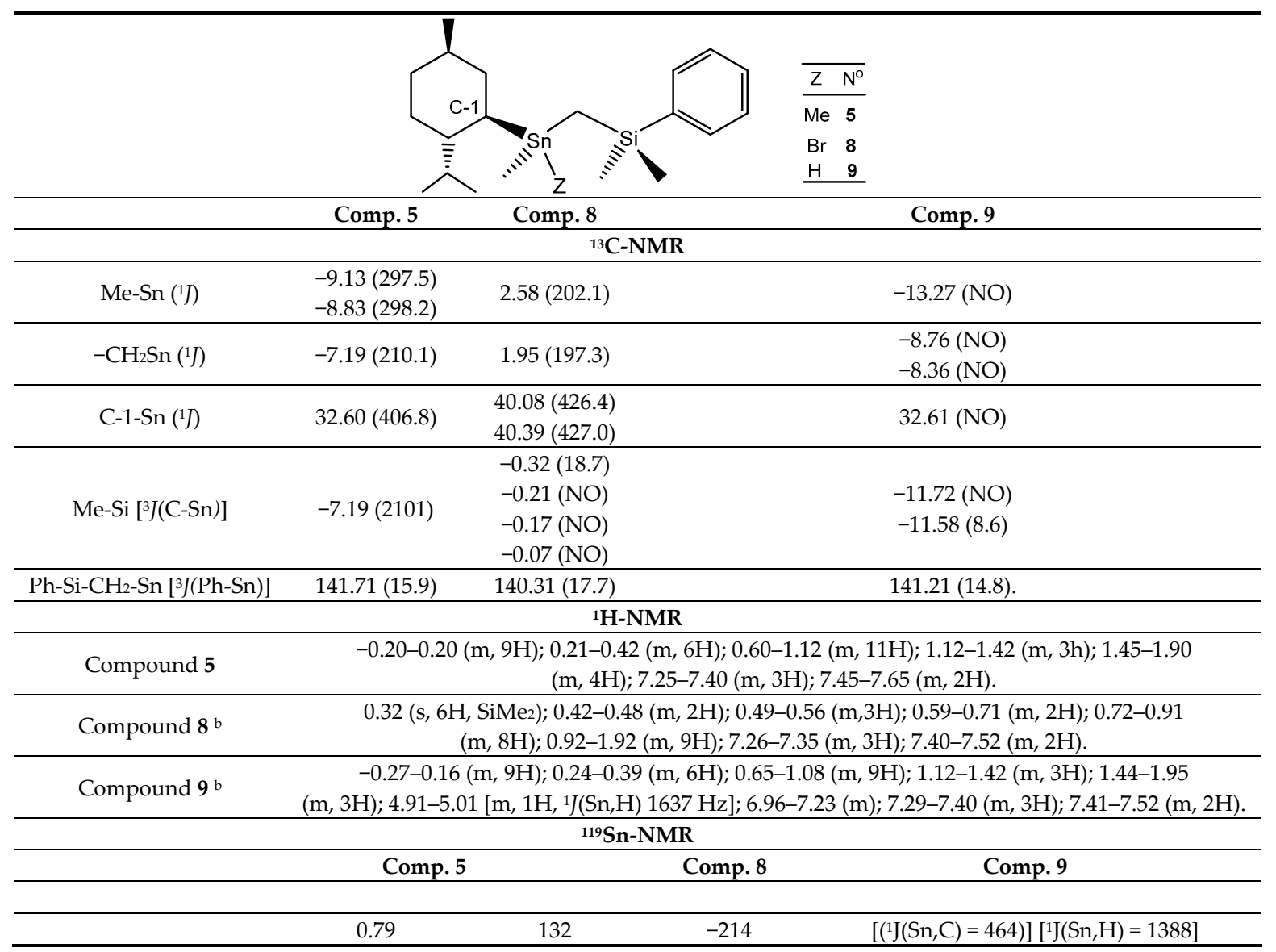

a In $\mathrm{CDCl}_{3}$ (compounds 5 and 8) and $\mathrm{C}_{6} \mathrm{D}_{6}(9)$; chemical shifts in ppm; nJ(Sn,C) and nJ(Sn,H) coupling constants (in brackets) in Hz. ${ }^{\mathrm{b}}$ Mixture of diastereomers.

These new organotin hydrides will be used in studies connected with the stereoselective reduction and hydrostannation of prochiral unsaturated systems.

Acknowledgments: CONICET and UNS of Argentina supported this work. A fellowship from CIC-PBA to VFT is gratefully acknowledged.

Conflicts of Interest: The authors declare no conflicts of interest.

\section{References}

1. Davies, A. Organotin Chemistry; VCH Verlagsgesellschaft: Weinheim, Alemania, 2004.

2. Organotin Reagents in Cross-Coupling, Chapter 4. In Metal-Catalyzed Cross-Coupling Reactions; Diederich, F., Stang, P.J., Eds.; Wiley-VCH: Weinheim, Alemania, 2001.

3. Marshall, J.A. Organotin Chemistry. In Organometallics in Synthesis: A Manual; Schlosser, M., Ed.; John Wiley \& Sons Ltd.: Hoboken, NJ, USA, 2002.

4. Dodero, V.I.; Koll, L.C.; Mandolesi, S.D.; Podestá, J.C. Stereoselective Hydrostannation of Substituted Alkynes with Trineophyltin Hydride. J. Organomet. Chem. 2002, 650, 173. 
5. Dodero, V.I.; Mitchell, T.N.; Podestá, J.C. Synthesis and some Reactions of Tris(phenyldimethylsilyl methyl)tin Hydride. Organometallics 2003, 22, 856.

6. Faraoni, M.B.; Dodero, V.I.; Podestá, J.C. Synthesis and some stereoselective radical additions of bis[(phenyldi methylsilyl)methyl]tin dihydride. Arkivoc 2005, 12, 88-97.

(C) 2019 by the authors. Licensee MDPI, Basel, Switzerland. This article is an open access article distributed under the terms and conditions of the Creative Commons Attribution (CC BY) license (http://creativecommons.org/licenses/by/4.0/). 